\title{
Descriptive Reference Fixing and Epistemic Privileges ${ }^{1}$
}

\author{
[FIXAÇÃO DE REFERÊNCIA DESCRITIVA E PRIVILÉGIOS EPISTÊMICOS]
}

\author{
Marco Rufino * \\ University of Campinas, Brazil
}

\begin{abstract}
Donnellan (1977) argues for a radical limitation of Kripke's (1980) thesis concerning the possibility of contingent truths knowable a priori as a result of descriptive reference fixing for names. According to the former, in the absence of some form of acquaintance between the speaker and the object of knowledge, there can be no de re singular knowledge (or even belief) envisaged by Kripke. And in the presence of acquaintance (which typically takes the form of perceptual contact), there can be no a priori knowledge. On the other hand, Jeshion (2001) argues that Donnellan's main argument is fundamentally flawed. She explores a loophole intentionally (and explicitly) left open by Donnellan to say that he has not ruled out an alternative explanation for the problem that motivates the revision of Kripke's thesis. In this paper, I access Jeshion's argument against Donnellan. As I intend to show, she does not fully appreciate a second loophole in Donnellan's account that offers a more appropriate way of seeing Kripke's examples.
\end{abstract}

KEYWORDS: Kripke; Donnellan; Jeshion; contingent a priori truths
Resumo: Donnellan (1977) defende uma limitação radical da tese de Kripke (1980) sobre a possibilidade de verdades contingentes conhecíveis a priori como resultado da fixação de referências descritivas para nomes. De acordo com o primeiro, na ausência de alguma forma de familiaridade entre o falante e o objeto de conhecimento, não pode haver nenhum conhecimento (ou mesmo crença) singular de re concebido por Kripke. E na presença de familiaridade (que normalmente assume a forma de contato perceptivo), não pode haver conhecimento a priori. Por outro lado, Jeshion (2001) argumenta que o principal argumento de Donnellan é fundamentalmente falho. Ela explora uma lacuna intencionalmente (e explicitamente) deixada em aberto por Donnellan para dizer que ele não descartou uma explicação alternativa para o problema que motiva a revisão da tese de Kripke. Neste artigo, acesso o argumento de Jeshion contra Donnellan. Como pretendo mostrar, ela falha em apreciar uma segunda lacuna nas considerações de Donnellan que oferece uma maneira mais apropriada de ver os exemplos de Kripke.

Palavras-Chave: Kripke, Donnellan, Jeshion, contingent a priori truths

\section{INTRODUCTION}

Tn a classic paper Donnellan (1977) argues for a radical limitation of an epistemological thesis defended by Kripke (1980) concerning the possibility of some contingent truths being knowable a priori as a result of stipulations of the reference of names. Donnellan argues that, in the absence of some form of acquaintance

* Professor of Philosophy at the Department of Philosophy, University of Campinas, Brazil. Email: ruffinomarco@gmail.com 
between the speaker and the object of knowledge, there can be no de re singular knowledge (or even belief) envisaged by Kripke. And in the presence of acquaintance (which typically takes the form of perceptual contact) between speaker and the object of belief, there can be no a priori knowledge. This seems to undermine Kripke's thesis that, solely as a result of stipulation (more precisely, stipulative reference fixing of names), a speaker may have contingent a priori knowledge. Donnellan's line of criticism became very influential and was followed, if not in the letter at least in spirit, by many detractors of Kripke's views on contingent a priori truths, including some notorious Millians (such as Salmon (1986) and Soames (2003)) as well as non-Millians (such as Evans (1979)). In an also influential paper, Jeshion (2001) argues in different ways against Donnellan's position, but her central point is that his main argument is fundamentally flawed. She explores a loophole intentionally (and explicitly) left open by Donnellan himself in his argument to say that he has not ruled out an alternative explanation for the problem that he points out in Kripke's thesis.

The dialectic of the present paper is the following: I shall argue not exactly for Donnellan's position concerning the impossibility of de re knowledge, but shall explore yet another loophole left open by Donnellan to argue that Jeshion's appreciation of his argument is incomplete. Donnellan gives some hint concerning the kind of illocutionary act involved in the relevant sort of reference fixing. (Unfortunately, he does not develop further his own line of thought.) But given his indication of this path (not taken by himself), we can see that there is something wrong with Jeshion's diagnosis of Donnellan's argument and also offer a different diagnosis for the argument's failure. Jeshion's focus is in a way different from mine: she wants to argue against a trend in Millianism that does not accept acquaintanceless de re knowledge. She places, as we'll see, less importance on the question whether or not the cases presented by Kripke generate a priori knowledge (and even less on the fact that they are of contingent truths) than on the the question whether or not they can generate genuine de re knowledge (or belief) under the optic of Millianism. In this paper, I shall forgo any discussion of her constructive arguments for the possibility of de re attitudes based on descriptive reference fixing (I basically agree with her on that, and shall not argue for it). I shall rather concentrate on the negative part of her argument, i.e., on what she thinks is wrong with Donnellan's take on Kripke's contingent a priori truths. This is instructive, I believe, because it helps to get a different (and better) perspective on the nature of contingent a priori truths.

\section{1- Donnellan on Kripke: The De Re Principle}

Let me start by recalling the elements of a classic discussion. Kripke (1980) defends the thesis that proper names are rigid designators. One consequence of it is that, as Kripke argues, they cannot be seen as having their meaning given by ordinary descriptions. However, Kripke also distinguishes between two distinct roles that we may attribute to descriptions in their relation to names: one may see them as giving the meaning of a name or one may see them as being used to fix the reference of a name. For him, while it is wrong to see descriptions as playing the former role (because, among other reasons, the name behaves differently from the description in modal contexts), it is correct to say that they play the latter role in some cases. The fact that descriptions might be used to fix the reference of some names gives rise to the following situation: someone stipulates that ' $\mathrm{N}$ ' is to refer to the only $\mathrm{x}$ such that $\Phi(x)$ (for brevity, the $(\mathrm{x}) \Phi(x)$ ). Now if the description used to fix the reference $(t h e(x) \Phi(x))$ is 
not rigid, then the stipulator might know a priori that $\mathrm{N}$ is the $(x) \Phi(x)$ in the sense that no special empirical test or evidence is needed to check its truth, since it is the product of a stipulation. One of Kripke's classic examples is of the length of the standard meter stick $S$ : for the person who stipulates that 'One meter' is to refer to the length of $S$ at $t_{0}$, no measurement of $S$ at $t_{0}$ is required to know the truth of the proposition that the length of $S$ at $t_{0}$ is one meter. However, this is a contingent truth, since $S$ could have other lengths at $t_{0}$. For some reason, Donnellan does not so much concentrate on this example, but on the second classic example presented by Kripke, the one inspired on the historic episode of the astronomer Leverrier baptizing (in 1846, before Neptune was effectively observed for the first time) as 'Neptune' the heavenly body responsible for some observed perturbation in Uranus' orbits. Kripke concludes that

If Leverrier indeed gave the name 'Neptune' to the planet before it was even seen, then he fixed the reference of 'Neptune' by means of the description just mentioned. At that time he was unable to see the planet even through a telescope. At this stage, an a priori material equivalence held between the statements 'Neptune exists' and 'some one planet perturbing the orbit of such and such other planets exists in such and such a position', and also such statements as 'if such and such perturbations are caused by a planet, they are caused by Neptune' had the status of a priori truths. Nevertheless, they were not necessary truths, since 'Neptune' was introduced as a name rigidly designating a certain planet. (KRIPKE, 1980, n. 33)

Although Kripke does not formulate his thesis in terms of propositions (let alone in terms of singular propositions), we can follow the mainstream interpretation of him as saying that, in virtue of his stipulation, Leverrier had a priori knowledge of the contingent singular proposition ${ }^{2}$ that if such and such perturbations are caused by a planet, they are caused by Neptune. In this sense, we can talk of an epistemic priviledge in the sense that Leverrier came to know something (or even to have epistemic access to an otherwise unthinkable proposition) solely in virtue of making a linguistic stipulation.

Donnellan disagrees. He sees as preposterous the supposition that one should gain knowledge of contingencies simply in virtue of stipulations. One thing, he says, is to have knowledge that the sentence 'Neptune is the cause of such and such perturbations (if there is one)' is true. This is purely metalinguistic knowledge, comparable to, e.g., the knowledge that someone completely ignorant of Mandarin might nevertheless know that a particular sequence of words in this language is a true sentence (this might be because someone else, who is effectively fluent in Mandarin and a reliable source, told so). Quite another thing, according to Donnellan, is to know the truth expressed by the sentence. In our case, to know the proposition that contains Neptune as a constituent. The second kind of knowledge (which is genuinely de re) is more demanding in the sense that there are further conditions to be met.

In order to prove his point, Donnellan presents some examples in which it would seem quite strange to attribute knowledge to the stipulator. Or, better said, situations in which, although it seems intuitively correct to attribute to the stipulator knowledge about an object under a particular name of it, it seems intuitively incorrect to attribute the same knowledge under a different designation of the same object. Here is the first example ${ }^{3}$ :

Consider the description, "the first child born in the 21 st century." Even though the denotation, if there is one, does not yet exist [...] we can by stipulation introduce a rigid designator for that person, if there is to be one. So, following Kaplan, we shall stipulate that providing the first child born in the 21 st century will exist, the sentence 
"Newman 1 will be the first child born in the 21 st century" shall express a contingent truth. Let us now imagine that just after midnight on New Century's Eve a child is born who is firmly established to be the first born of the century. He is baptised "John," but those of us who are still around, remembering our stipulation, also call this child "Newman 1." Now it seems to me that it would be outrageous to say that some twentyfive years or so before his birth, we knew that John would be the first child born in the 21 st century. Suppose one of us, living to a ripe old age, were to meet John after he has grown up a bit. Would it be true to say to John, 'I call you 'Newman 1' and Newman 1, I knew some twenty-five years or so before your birth that you would be the first child born in the 21st century"? (DONNELLAN, 1977, p. 20)

And here is the second example:

The Neptunians are watching on their interplanetary videoscope; they see and hear Leverrier perform his act of stipulation [...]. They know that their planet is the cause of the perturbations in the orbit of Uranus. Would they be justified in concluding that the Earthling has learned or come to know that their planet is the cause? It seems to me that the answer is obviously that they would not. Suppose they call their planet "Enutpen." Would they be justified in saying, in Enutpenese, that the Earthling now knows that Enutpen is the cause of those perturbations? Again I think not. (DONNELLAN, 1977, p. 20-1)

An important detail is that in these cases, the terms referring to the objects of knowledge ('Newman I', 'you', 'Neptune' and 'Enutpen') are taken to be "rigid designators", by which Donnellan understands directly referential singular terms. ${ }^{4}$ The Newman I and the Enutpen situations above are meant by Donnellan as illustrating a situation in which the stipulator apparently has de re knowledge concerning the object named in the stipulative reference fixing, but this is actually illusory, because the knowledge report may be true using one name for the object of belief, and false using another name (or demonstrative) for the same object. But if there were genuine de re knowledge in these situations, the reports should be insensitive to the particular referential term employed. In both situations we have a conflict with Donnellan's principle, which he presents as a necessary condition for de re knowledge:

If an object is called by one name, say "N", by one group of people, and by another name by a second group, say "M", and if, in the language of the first group " $\mathrm{N}$ is $\Phi$ " expresses a bit of knowledge of theirs and if "is $\psi$ " is a translation of "is $\psi$ " into the language of the second group then if the relevant facts are known to the second group, they can truly say that the first group "knew that $\mathrm{M}$ is $\psi$ '”. (DONNELLAN, 1977, p. 22)5.

I follow Jeshion and call this the De Re Principle. ${ }^{6}$ And I shall call Donnellan's Problem the fact that there is a strain of the De Re Principle in cases like Newman I and Neptune. Donnellan's own explanation for Donnellan's Problem is that there is no genuine de re knowledge in these situations. The impression that there is some sort of knowledge involved comes, for him, from the fact that we do have the purely metalinguistic knowledge that 'Newman I is the first child born in the 21rst century' expresses a true proposition, and that Leverrier does have the purely metalinguistic knowledge that 'Neptune is the cause of the perturbation in the orbits of Uranus' expresses a true proposition. But here, as said before, there is a big difference between knowing that a sentence is true, and knowing the truth that it expresses. In other words, Donnellan thinks that the best explanation for Donnellan's Problem is that there is no de re knowledge involved in the examples, but just metalinguistic knowledge. 


\section{2 - DONNELLAN's FirST LOOPHOLE AND JEShION's CRITICISM}

Donnellan says that the De Re Principle is a "loose" principle. And this is not, as one could expect, because of issues related to the vagueness of the notion of knowledge or of de re but, as he admits (and Jeshion bases her main argument on this), because there are exceptions, i.e., cases in which there is a strain of the De Re Principle (i.e., cases presenting Donnellan's Problem) and that are, nevertheless, cases of genuine de re knowledge. He makes a brief remark that such cases are those that exhibit a Frege's Puzzle structure ${ }^{7}$. E.g., although the Babylonians were inclined to say that the heavenly body that they called 'Hesperus' was the first to appear in the evening sky but were not at the same time inclined to say the same about the heavenly body that they called 'Phosphorus', we are correct in saying that the Babylonians knew that Phosphorus (or even Venus) is the first heavenly body to appear in the evening sky. That is to say, Donnellan sees a fundamental difference between cases involving descriptive referencefixing such as Kripke's Neptune case and cases that have a Frege's Puzzle structure, although both classes of cases exhibit Donnellan's Problem. But he does not explain the difference. Actually, there are two gaps in Donnellan's account:

(1)-he does not explain the exceptionality of cases with a Frege's Puzzle structure, i.e., why they might constitute cases of genuine de re knowledge despite the fact that they exhibit Donnellan's Problem (i.e., strain the De Re principle);

(2)-he offers no reasons for not counting descriptive reference fixing cases as Frege's Puzzle cases.

Jeshion criticizes Donnellan on both accounts.

Regarding the first gap, she offers herself an account aimed at closing it, an account in terms of perspectives or guises that the subject has towards the object of knowledge (or belief), and one that she believes that Donnellan endorses too. I shall not, in the limited scope of this paper, discuss her account of how different guises explain the Frege's Puzzle structure in some cases of genuine de re knowledge.

Once she has this account, she moves to the second gap, and argues, contra Donnellan, that there is no reason for keeping descriptive reference fixing apart from Frege's Puzzle cases. This means that, for her, the strain of the De Re Principle observed in the Neptune and Newman I cases are not unequivocal signs that there is no de re knowledge (or belief) involved in them. ${ }^{8}$ Jeshion not only claims that there is no reason for excluding Donnellan's cases as instances of Frege's Puzzle situations, but she also proposes an argument to the effect that all descriptive reference fixing must generate cases of this kind:

Now, if we assume that the stipulation gives rise to the non-meta linguistic de re belief about $\alpha$ that $\alpha$ is F, we have a special case of Frege's Puzzle-a single belief content is uninformative (and directly a priori justified) to the stipulator but informative (and justified empirically or by proof) to the rest of us. In other words, and this is just the point I have been pressing, if the stipulator can have the relevant non-meta-linguistic de re belief, there will always be a Frege's Puzzle structure in place due to the alternative guises under which stipulators and nonstipulators grasp the relevant proposition. (JESHION, 2001, pp. 122-3)

In other words, she takes the stipulation that underlies the descriptive reference fixing as creating one more perspective to the named object, namely, the one of the stipulator, but then there can be no a priori knowledge involved since there are other perspectives, namely, the ones of the non-stipulators, and the identities between these perspectives is always informative. But here is a minor flaw in her argument. First, the main point of Kripke's examples is the existence of contingent a priori truths from the perspective of 
the stipulator. (And this is also the focus of Donnellan's criticism; he challenges the fact that the stipulator can have a priori knowledge given only her background assumptions.) So, the appeal to the perspectives of other people besides the stipulator does not seem to be relevant here.

We could so summarize the dialectic of the Jeshion-Donnellan controversy:

128 Donnellan's main point is that in cases of descriptive reference fixing such as the Neptune and the Newman I cases we can have a strain of the De Re Principle (this straining is what I called Donnellan's Outcome). Now Donnellan thinks that Donnellan's Outcome is a sign (or the best explanation for it is) that there is no genuine de re knowledge in these cases. Cases that exhibit a Frege's Puzzle structure (like the Hesperus-Phosphorus case) escape this diagnosis, i.e., in these latter cases we can have something like Donnellan's Outcome coexisting with genuine de re knowledge or belief (or, at least, Donnellan's Outcome is not, in these cases, an unequivocal sign of the absence of de re knowledge or belief). But cases involving descriptive reference fixing are not to be counted as Frege's Puzzle cases. We have two big gaps in Donnellan's account: First, Donnellan does not explain the exceptionality of cases with a Frege's Puzzle structure and, second, he offers no reasons for not counting descriptive reference fixing cases as Frege's Puzzle cases. Jeshion criticizes Donnellan on both accounts. Regarding the first gap, she offers herself an account aimed at closing it, an account in terms of perspectives or guises that the subject has towards the object of knowledge (or belief), and one that she believes that Donnellan would endorse too (despite the fact that he is silent about it). Once she has this account, she moves to the second gap, and argues, contra Donnellan, that there is no reason for keeping descriptive reference fixing apart from Frege's Puzzle cases.

\section{3 - Donnellan's Second Loophole: The Declarative Dimension of DESCRIPTIVE REFERENCE-FIXING}

A plausible hypothesis is that Donnellan sees something really crucial in the fact that, in the Neptune and similar cases, and contrary to the Frege-Puzzle-like cases, one of the names is being fixed by a stipulation. If this is so, one cannot invoke the ignorance of the Babylonians concerning the fact that Phosphorus is the first heavenly body to appear in the evening. For they were the stipulators of the name 'Phosphorus' as referring to the first heavenly body to appear in the evening. Jeshion says:

What's more, Donnellan offers us no supplementary argument to rule out this explanation. He says that the structure exhibited by the Hesperus-Phosphorus case does not seem to be present in the Neptune-type case, but why should we believe that? (p. 121)

But I think that she does not fully appreciate yet another loophole left open by Donnellan in a very brief and underdeveloped passage. He gives a hint about how he understands stipulative reference fixing in the following passage:

[B]ecause I think it somewhat illuminating to do it this way, I am going to propose instead that we think of the introduction as consist ing of stipulating that a certain sentence shall express a contingent truth. If we want to introduce the name " $\mathrm{N}$ " by means of the de scription of "the $\Phi$ " then the formula we would use would be: (a) Provided that the $\Phi$ exists, let " $\mathrm{N}$ is the $\Phi$ " express a contingent truth. It is a condition on the stipulation that the $\Phi$ exists and should it turn out that it does not, the stipulation, we might say, has been an unhappy one and not to be taken as being in effect. (p. 19) 
How can that be so? We normally take stipulative descriptive reference fixing as being something of the following form:

(N) ' $\mathrm{N}$ ' is to refer to (the $\mathrm{x}$ ) $\Phi \mathrm{x}$

but Donnellan suggests that it can be taken as

$\left(\mathrm{N}^{*}\right)$ Let ' $\mathrm{N}$ is (the $\mathrm{x}$ ) $\Phi \mathrm{x}$ ' express a contingent truth

And he considers "somewhat illuminating" to do it this way. Jeshion immediately protests: "This will not do. By stipulation one cannot make it true that ' $N$ is an F' expresses a contingent truth. The modal status of the proposition is not something that avails itself to stipulation." (2001, Footnote 8). She has a point if Donnellan's emphasis in this passage is placed on the modal status of the proposition expressed. But I think that there is a way of reading it as having emphasis not not on the modal status, but rather on the 'truth' of the proposition: one cannot fix by stipulation that a proposition is contingent, but one can fix by stipulation that a contingent proposition is true.

How is that possible? From the perspective of speech act theory, this is something that can be achieved, but not by an ordinary assertion; this requires a different kind of illocutionary act. Here I follow the account and taxonomy of speech acts presented in Searle (1979) and Searle and Vanderveken (1985). In their perspective, stipulations belong to the category that they call declarative speech acts, and the point of such acts is to make true a propositional content by means of the very utterance. There are contingent propositional contents that can be made true by the very utterance. E.g., 'you are my lawyer' can be made true if I decide to nominate you my lawyer, or 'you are fired' can be made true if I have the required authority over you. If the content is first made true by the utterance, it must be contingent, for otherwise it would be true anyway and the utterance would be simply irrelevant. Some contents can be made true if the declaration is successful, but there are other contents that cannot be made true because it is not in our power to bring about their truth. E.g., I cannot successfully say 'I hereby turn the sky red' because turning the sky red is not something that can be done by means of an utterance, contrary to those that employ a performative verb. It is a fact noted by Searle that, although there is nothing wrong from the grammatical point of view with a performative formula such as 'I hereby turn the sky red', it is simply a fact that we, human beings, cannot simply by means of the utterance turn the sky red. It is not a matter of the semantic of the verb involved, but simply a metaphysical limitation on our part. Some actions can be successfully performed by means of utterances (I mean, of course, actions other than just uttering something) but some cannot be so performed.

The point is that, in the Neptune case, we do not have an ordinary assertion of an identity that is true or false independently of the assertion; as the passage on contingency by stipulation makes clear, Donnellan sees the Neptune case as one in which the identity is made true (or instituted) by the very act, hence, it must be a declaration from the perspective of speech act theory. That could explain why the Neptune case is not a case like Hesperus-Phosphorus, and has to be treated separately. I repeat: Donnellan does not say this explicitly, but suggestion for this interpretation is given in his remark on making a propositional content true by stipulation.

Another way of presenting my point would be the following: Jeshion assumes (and takes Donnellan to do so as well) that there are distinct ways (or "guises") of taking the objects of belief corresponding to the names 'Hesperus' and 'Phosphorus', and these perspectives explain the apparent strain of the De Re Principle, for there 
should presumably always be a strain in such principle whenever there is more than one perspective associated with the same object of belief. (There is always the possibility that an epistemic agent is inclined to assent to ' $a$ is $\Phi$ ', but not inclined to assent to ' $b$ is $\Phi$ ' although 'a' and ' $b$ ' refer to the same object and are directly referential.) However, it is doubtful that things should be that simple if the two perspectives are brought together by an act of stipulation: in this case, we must consider an identity of the form $a=t h e(x)$ $\Phi(x)$ to be made true by the act of stipulation. Since the $(x) \Phi(x)$ is a non-rigid designator, the identity above is a contingent one, and its content is first made true by the stipulation as a declarative act. I.e., the stipulation is not just of the same kind of a simple (descriptive) assertion of an identity. For the latter, one might conclude with Jeshion that there is always the question of multiple perspectives and, hence, that there is a Frege's Puzzle structure that explains the strain of the De Re Principle. But regarding the former, it seems that Jeshion does not fully appreciate the fact that descriptive reference fixing made by a stipulation requires a special illocutionary act with some effects different from mere assertions. ${ }^{9}$ In the case of a stipulation we are not dealing with the assertion of an ordinary identity (which might be true or false independently of the assertion), but with one that is first made true by the linguistic act, and hence there is no residual doubt for the stipulator.

One might ask: what about other people (i.e., the non-stipulators)? Here is a perspective: if the fact generated by the stipulation is seen as an institutional fact, and if the stipulator has the required form of authority for such an act, the non-stipulators are under the same commitment of taking the stipulated identity as something made true by the sole act of stipulation and, hence, no additional empirical evidence is necessary for knowing that it is true. ${ }^{10}$ If the audience recognizes the institutional authority of the stipulator, this means that the coordination is shared by the stipulator and the audience, that is to say, if the stipulator has a priori knowledge that $a$ is $\Phi$ in virtue of the stipulation that 'a' refers to the $(\mathrm{x}) \Phi(x)$, the audience also shares that recognition, and the main justification of such knowledge is, as I said, the successful stipulative act itself.

If this is so, then Donnellan can resist Jeshion's claim that exactly the same Frege's Puzzle structure is present in cases of stipulative reference-fixing as it is in cases like Hesperus-Phosphorus. ${ }^{11}$

\section{4 - Some Concluding REMARKS}

My conclusion is that Jeshion is partly wrong: Donnellan cannot see the same structure in the Neptune case as in the Hesperus-Phosphorus case because, in the former, but not in the second, we have a proposition being made true by the stipulation, which is a declarative act (not an assertion). So, she offers a wrong diagnosis of what is wrong with Donnellan's argument. My point is that she fails to fully appreciate Donnellan's second loophole, which is the suggestion that the stipulation is not, like cases of identities having a Frege's Puzzle structure, an ordinary assertion.

But Donnellan is also wrong: he thinks that making a contingent propositional content true by stipulation is absurd ("Only God could do it"). But it is not. A contingent content might be the subject of a stipulation in some cases, and there is nothing mysterious about this. Not all contingent propositional contents can be made true by stipulation (although there is nothing wrong grammatically with it), but some can. The standard meter case is a good example of a contingent content that can be made true by stipulation (i.e., one can stipulate that ' $\mathrm{S}$ is one meter long at $\mathrm{t}_{0}$ ' expresses 
a truth, if one has the authority for doing so). But, of course, one cannot stipulate an astronomical fact.

This brings us to a difference between the Neptune case and the meter case. Not all cases discussed by Kripke are alike. Kripke thinks that the notion of contingent $a$ priori truth is unproblematic probably because he thinks that all cases are like the meter case in which a contingency (i.e., a standard of measurement) can be made true by stipulation. And Donnellan thinks that all cases of contingent a priori truths discussed by Kripke are doomed to failure probably because he sees all of them similar to the Neptune case, in which the contingency cannot possibly be made true by stipulations. Both Kripke and Donnellan are partially right and partially wrong.

\section{REFERENCES}

DONNELLAN, K. S. The contingent a priori and rigid designators. Midwest Studies in Philosophy, 2(1):12-27, 1977.

DUMMETT, M. Frege: Philosophy of Language. Harvard University Press. 1973.

EVANS, G. Reference and contingency. The Monist, 62(2):161-189, 1979.

JESHION, R. Donnellan on Neptune. Philosophy and Phenomenological Research, 63(1):111-135, 2001.

JESHION, R. . Acquaintanceless de re belief. In CAMPBELL, J., O'ROURKE, M., AND SHIER, D. (Org.). Meaning and Truth. Investigations in Philosophical Semantics, Oxford University Press, 2002. p. 53-78.

KRIPKE, S. Naming and Necessity. Harvard University Press, 1980.

RUFFINO, M. Contingent a priori truths and performatives. Synthese, pages 1-21, 2020.

SALMON, N. Frege's Puzzle. Ridgeview Publishing Company, 1986.

SEARLE, J. A taxonomy of illocutionary acts. In SEARLE, J. (Org.). Expression and meaning: Studies in the theory of speech acts: Cambridge University Press, 1979. p. 1-29.

SEARLE, J. and Vanderveken, D. Foundations of illocutionary logic: Cambridge University Press, 1985.

SOAMES, S. Philosophical Analysis in the Twentieth Century. Volume I, The Dawn of Analysis: Princeton University Press. 2003.

\section{Notas}

1 Research for this paper was supported by grant 2018/17011-9 from FAPESP and grant 428084/2018-4 from CNPq.

2 Singular because the only content of the name 'Neptune', according to Kripke, is the object Neptune.

3 To understand the point of this passage one should remember that it was written some decades before the 21 st century.

4 The first section of Donnellan (1977) is concerned with the question as to whether ordinary names are indeed rigid or not. Donnellan concludes, against Kripke, and in view of an argument raised by Dummett (1973), that there is no conclusive evidence that they must be taken this way. But he thinks that they could be introduced with the intention (and explicit convention) of being rigid. In both passages he is assuming that the names were explicitly introduced as rigid.

5 Donnellan formulates a second analogous principle, only instead of another name ' $M$ ', the second group of people uses a demonstrative for the same object.

6 Although it is formulated as a condition for de re knowledge, it also applies to weaker things such as de re belief or simply having epistemic access to (or thoughts with the content of) singular propositions.

7 Donnellan (1977), Footnote 22.

8 She illustrates both kinds of cases with two situations: one in which someone sees a person on a TV show being called by the name 'Newman', and does not recognize that person as one 
of her relatives that she knows personally from family meetings and that she calls 'Grandpa Joe'. On the TV show 'Newman' is presented as the only person having a certain property. In this situation it seems correct if we report her belief by saying that she knows that Grandpa Joe is . The second situation is one in which someone proposes to name 'Oldman I' for the only person having a property without knowing that that person is the same as the one she calls 'Grandpa Joe'. In both cases we have Donnellan's Problem. And the second, but not the first, is a case of stipulative descriptive reference fixing. She claims that the explanation for the strain in the second case is the same as for the first case.

9 It is curious that in this paper she quotes her own Jeshion (2002) in which she does recognize that stipulative reference fixing must be a performative. But she does not develop this insight any further except in discussing the felicity condition of existence of the reference.

10 For further details, see Ruffino (2020).

11 He does not articulate this view, but his paper has the elements for doing so. 